\title{
Patient-centered assessments: how can they be used in dental clinical trials?
}

\section{Matheus França PERAZZO(a) Júnia Maria SERRA-NEGRA ${ }^{(a)}$ iD Ramon Targino FIRMINO(a) (ID Isabela Almeida PORDEUS(a) Paulo Antônio MARTINS-JÚNIOR(a) (iD) Saul Martins PAIVA(a) \\ (a) Universidade Federal de Minas Gerais}

- UFMG, School of Dentistry, Department of Pediatric Dentistry, Belo Horizonte, MG, Brazil.
Declaration of Interests: The authors certify that they have no commercial or associative interest that represents a conflict of interest in connection with the manuscript.

\section{Corresponding Author:}

Saul Martins Paiva

E-mail:smpaiva@uol.com.br

https://doi.org/10.1590/1807-3107bor-2020.vol34.0075

Submitted: September 9, 2019

Accepted for publication: September 22, 2019 Last revision: June 8, 2020
Abstract: Recently, there has been greater interest in adopting a more holistic approach to healthcare. However, this trend should not limit itself merely to the notion that a human being lies behind the mouth being treated. Rather, it should embrace the understanding that this human can actively participate in and contribute to the treatment process. Patient Report Outcome Measures (PROMs) and Patient Report Experience Measures (PREMs) provide means for measuring data from the patient's perspective, and enable health-related feelings and functions to be evaluated. Accordingly, this critical review aims to provide definitions, rationales and applications of patient-centered approaches in dental clinical research. Some patient-centered constructs are especially relevant to dental clinical trials, such as oral healthrelated quality of life, pain/discomfort, aesthetics and satisfaction concerning treatment and services. The selection and application of patient-reported measures can vary according to condition (generic, disease-specific or treatment-specific) and to the specific population evaluated (age and cognitive impairment). These measures can help weigh risks and benefits, as well as assess the cost effectiveness of treatments, thus influencing treatment recommendations and health policies. The incorporation of these measures into a professional's daily life not only represents an improvement in professional performance, but also addresses a humanitarian concern.

Keywords: Clinical Trial; Health; Patient Outcome Assessment; Patient-Reported Outcome Measures; Surveys and Questionnaires.

\section{Introduction}

Oral health is a multidimensional concept which cannot be completely understood through a restricted unidirectional approach applied by professionals toward patients. ${ }^{1,2}$ The patient-centered method of exploring health variables has become more common over the decades, and more influential in developing clinical research. ${ }^{3,4}$ Accordingly, a trend has arisen among companies and researchers of not viewing patients merely as subjects, but as informed collaborators whose participation is key to the overall success of clinical trials. ${ }^{3}$ Based on this view, the Committee on the Quality of Health Care in America has recommended that patient values should guide all clinical decisions, and the impact of these decisions on improving the Health Care System. ${ }^{1}$ 
Patient Report Outcome Measures (PROMs) and Patient Report Experience Measures (PREMs) provide means for measuring intervention benefits/ risks by evaluating concepts related to how patients feel or function with respect to their health. ${ }^{4}$ The development of PROMs and PREMs has given patients a voice in research and health services..$^{5,6,7}$ The results of these measures have a potential influence on treatment recommendations and/or health policy. ${ }^{5}$ Therefore, this review aims to give definitions, examine relevancies and discuss applications of patient-centered approaches in clinical research dentistry.

\section{PROM overview}

PROMs are identifiable, valid and reliable instruments that evaluate a patient's health condition, as reported directly by the patient. The concepts, events, behaviors or feelings measured by PROMs can be either readily observed (i.e., aesthetic) or unobservable, known only to the patient, and not easily verified (i.e., pain, quality of life)., ${ }^{4,5}$ PROMs were originally developed to compare groups of individuals in clinical trials and population studies. ${ }^{5,6}$ These measures enable making a systematic assessment of the patient's perspective of treatment effectiveness, by providing information that could be lost if a non-validated method were used, or if the patient were disregarded. ${ }^{4,7}$ Therefore, PROMs can help evaluate patient progress, by enhancing the communication between dentist and patient, and/or helping to improve the quality of health services. ${ }^{8}$

PROMs can be generic, disease-specific or treatment-specific. Generic instruments are applicable in evaluating a broad scope of diseases/conditions and also in analyzing cost-effectiveness. ${ }^{4,9}$ However, these instruments are less sensitive in detecting small but clinically important differences, because they do not focus on the specific effects of the disease/condition. ${ }^{10}$ On the other hand, disease- and treatment-specific instruments are more sensitive in measuring aspects that are particularly salient. ${ }^{4}$

Age groups and cognitive impairment also influence PROM selection. ${ }^{4}$ Thus, the use of an instrument must respect the target population for whom it was validated. Otherwise, the PROM may not ensure the psychometrical soundness needed to evaluate a new group, for whom this instrument was not originally developed. ${ }^{11}$ PROMs developed for child/adolescent age groups consider age-related vocabulary, language comprehension, understanding the health condition, and duration of recall. If an instrument developed for an adult population is used on a child population, the answers given will probably not be valid or reliable.,12 Likewise, self-reported questionnaires may fail in data collection, if they are used on a cognitively impaired group, or on individuals in such a severe state that they are unable to communicate. ${ }^{4}$ In these cases, researchers should use a proxy-report questionnaire, where a third person answers the questions about the patient. ${ }^{13}$ The Food and Drug Administration (FDA) encourages the use of a proxy report together with patient self-reports, at the very start of the clinical trial, in cases when the patient is not expected to be able to answer the PROM. ${ }^{4}$

\section{PREM overview}

Whereas PROMs focus on outcomes, PREMs measure a patient's healthcare experience, and are primarily used for assessing and improving health services. ${ }^{6,7}$ PREMs can be used to evaluate the accessibility and effectiveness of healthcare processes, the quality of provider communication, healthcare coordination and continuity, patient involvement in healthcare decisions and management, and aspects of the humanity of care. ${ }^{6,714}$ Therefore, PREMs can provide feedback on health services based on patient expectations, and thus contribute toward redesigning the logistics and strategies of interventions. ${ }^{6,7}$

There are differences between PREMs and patient satisfaction rating scales. These satisfaction questionnaires are criticized for their lack of rigor and their narrow approach, since a patient may have a satisfactory experience regarding a service, but may have received poor care. More specifically in regard to clinical practice, PREMs are considered more accurate in encouraging patients to describe their actual experience about the care they received. ${ }^{14}$

\section{Patient-centered outcomes in dentistry}

A patient-centered evaluation in dentistry can be explored for different oral-related outcomes. Some 
of the concepts most widely investigated by patientcentered approaches are described below, focusing on their definition, applications and peculiarities.

\section{Oral health-related quality of life (OHRQOL)}

Oral health-related quality of life (OHRQoL) is a multidimensional construct concerning the subjective evaluation of oral health, functional and emotional well-being, and both expectations and satisfaction regarding healthcare and the sense of care.$^{15}$ In brief, it refers to the extent to which the individual's oral health affects the well-being and performance of his daily activities. ${ }^{16}$ It is a complex and dynamic construct, since quality of life is constantly evolving, is subject to change over time, and may vary according to the social, cultural or political context. ${ }^{17}$

The scientific community has been studying OHRQoL with greater attention, to the point that it has become a major area of research in dentistry. An electronic search in the Medline database of July 2019 , using the uniterm "oral health-related quality of life," resulted in 2047 studies. Studies evaluating this construct usually rely on questionnaires that cover a variety of oral conditions, such as dental caries, malocclusion and craniofacial anomalies. There are approximately forty instruments assessing OHRQoL in a wide range of populations. ${ }^{18}$

More important than knowing the characteristics of the instruments is understanding the clinical applicability of OHRQoL evaluations. Firstly, assessing quality of life allows an in-depth understanding of the repercussions of oral conditions on a subject's daily life, a perspective unlikely to be achieved based solely on the use of clinical indicators. ${ }^{19}$ This information can and should be used by the dentist to guide treatment goals and outcomes. ${ }^{15}$ As an example, from a clinical perspective, if the dentist is aware that the patient's orofacial appearance is the domain most impacted by a certain oral condition, his treatment can be planned to prioritize this demand.

An important advantage of the evaluations provided by this construct is being able to investigate treatment effectiveness from the patient's point of view. ${ }^{15}$ For example, dental bleaching has been found to change a patient's OHRQoL positively in aspects related to dental aesthetics, such as smiling, laughing and showing one's teeth without feeling embarrassed. On the other hand, tooth sensitivity and difficulty in performing dental hygiene due to pain were also reported, and negatively impacted quality of life..$^{20} \mathrm{~A}$ study conducted in Croatia compared three different prosthodontics devices, and enabled a significant improvement in OHRQoL after oral rehabilitation. OHRQoL was significantly higher in patients treated with overdentures supported by mini dental implants, compared with groups treated with removable partial dentures or complete dentures. ${ }^{21}$ The information gained from these investigations can empower both professionals and patients in treatment-related decision-making processes, by allowing a more rational and patient-centered decision.

Using OHRQoL instruments in a clinical setting can also ensure important information that can assist in weighing risks, benefits and treatment costs..$^{15} \mathrm{~A}$ previous investigation found that children submitted to dental treatment under general anesthesia had a significantly higher OHRQoL than those treated in multiple clinical visits, thus reinforcing the advantages of this procedure. ${ }^{22}$ In contrast, a study that evaluated OHRQoL before and after orthognathic surgery found that patients' OHRQoL improved in some aspects and worsened in others. ${ }^{23}$ Other investigations have also evaluated a patient's quality of life as an outcome of his interest in gaining the benefits and attenuating the risks related to treatment, such as using lasers for dentin hypersensitivity, microabrasion for dental fluorosis, fixed orthodontic appliances and temporomandibular joint disk surgery. ${ }^{24,25}$ Knowledge about the impact of these procedures on OHRQoL is of pivotal importance in deciding whether to advocate the adoption of such treatments.

\section{Pain and discomfort}

According to the International Association for the Study of Pain, pain is described as a complex, multidimensional phenomenon connected to unpleasant sensory and emotional experiences, related to actual or potential tissue damage, or described in terms of this damage. Patient-reported pain experience is affected by psychological (i.e., depression and catastrophizing) and demographic factors (i.e., age, sex and comorbidity). Discomfort is 
expressed as an unpleasant tactile sensation, feeling of constraint, soreness and pain. ${ }^{26}$

Pain experienced early in life may influence nociceptive processing over the rest of one's lifespan. ${ }^{27}$ Accordingly, studies on the neurobiology of pain in an individual's early development have found that newborns and children are already able to perceive pain..$^{27,28}$ However, there is a great difference in how individuals perceive, tolerate and report pain. Additionally, whereas an adult is usually able to verbalize feelings of pain, children perceive, understand, remember and verbalize pain in a different manner, owing to their cognitive immaturity. ${ }^{29}$

In dentistry, dental pain, or toothache, is defined as an orofacial pain originating from a tooth and/or adjacent structures. ${ }^{30}$ It is considered a major public health problem, because of its high lifetime prevalence, and because it involves all age groups worldwide. ${ }^{31}$ Several studies have demonstrated that dental pain presents strong functional, social, emotional and financial consequences, since it can cause suffering, nutritional and sleep disorders, and school and work absenteeism, depending on its intensity. ${ }^{32,33}$ Other studies have found that both children and adults are capable of remembering pain from previous visits to the dental office. ${ }^{34}$ Usually, dental pain is also accompanied by fear, anxiety and catastrophic thoughts, that is, negative reactions that interfere in the communication between the professional and the patient.

Since pain is a subjective experience, the assessment of pain should focus on the patient's description of how he feels pain, rather than only on nociceptive experiences. For this reason, many researchers worldwide have developed ways to transform pain from a subjective perspective into a normative aspect. In fact, accurate measurement of the quality and intensity of the pain may help guide precise diagnostic and therapeutic strategies. Moreover, pain plays an important role in setting realistic patient expectations, since preoperative pain levels have been shown to predict long-term outcomes following an intervention. ${ }^{35}$

Several different methods have been used to measure the perception or feeling of pain. As mentioned above, the subjective nature of the pain experience makes self-reported measures the gold standard for assessing feelings of pain ${ }^{29}$, mainly in older children and adults. However, in young children, proxy measures can be used. Some methods consider pain as one-dimensional, varying only in intensity, such as the Visual Analogue Scale. ${ }^{36}$ Onedimensional methods, albeit fast and easy to assess, provide only a report of the sensory experience of pain. ${ }^{37}$ On the other hand, multidimensional methods evaluate and measure different dimensions of pain, such as the McGill Pain Questionnaire. ${ }^{38}$ This questionnaire has an ordinal scale and a total of 20 items; it was designed to be self-completed. The instrument provides information on pain intensity, pain interference (in both physical and/or social activity, sleep, and relationships), and the mood/ cognitive effects of pain. ${ }^{37}$

Some instruments have been developed specifically focusing on oral/dental pain, such as the Dental Pain Questionnaire $(\mathrm{DePaQ})^{39}$ and the Dental Discomfort Questionnaire (DDQ). ${ }^{29}$ The $\mathrm{DePaQ}$ is composed of 14 items that evaluate location, frequency, and intensity of pain in the orofacial region. In addition, the instrument asks questions regarding tooth-specific signs and symptoms, including temperature sensitivity, biting sensitivity, and the combination of both. ${ }^{39}$ The DDQ is a reliable instrument for parents, non-dental healthcare workers, dental professionals and researchers in identifying dental pain in young children. ${ }^{29}$

\section{Aesthetics and satisfaction with treatment and services}

Orofacial appearance is a key component of physical appearance, and has a major influence on social interaction and psychological well-being, and on psychological development from early childhood to adulthood..$^{40}$ It is also correlated with a patient's self-perceived satisfaction. Appearance of lips and teeth constitutes two main features that define overall facial appearance. Both tooth appearance and smile appearance play an important role in the OHRQoL of patients, since they are critical components of judging facial attractiveness and personality, as well as psychological characteristics. ${ }^{41}$ 
Impaired orofacial aesthetics constitutes of one the most common reasons for patients to seek dental treatment, such as prosthodontics, restorations and orthodontics. In addition, aesthetic changes resulting from treatment are considered an important indicator when judging the final treatment results. ${ }^{42,43}$

Studies assessing satisfaction with aesthetics have confirmed that aesthetics is a key element for patients seeking dental treatment. Furthermore, studies have shown that patients with severe dental anxiety have less satisfaction with dental and facial appearance, and that the self-rating of orofacial aesthetics is related to both oral and psychological health. ${ }^{44}$ Color and arrangement of teeth were two of the most important features in the perception of the young adult population regarding personal dental appearance. ${ }^{45}$ A study with underprivileged Brazilian adolescents, which investigated the relationship between malocclusion and satisfaction with dental appearance, showed that female adolescents were more satisfied with their dental appearance than male adolescents. They observed that an increase in specific types of malocclusion was related to greater dissatisfaction with dental aesthetics. ${ }^{43}$

Although the visual analogue scale (VAS) has limitations concerning content validity, the present study found high but similar VAS scores for expectations before and satisfaction after treatment for all aspects evaluated (chewing, aesthetics, phonetics and comfort). ${ }^{46} \mathrm{~A}$ systematic review identified factors associated with treatment satisfaction of patients and caregivers, when applicable. The authors found that satisfaction was associated with the aesthetic and psychological benefits perceived. The quality of dental care was specifically related to dentist-staff-patient interactions. Conversely, they found that dissatisfaction was associated, overall, with treatment duration, pain and discomfort levels. ${ }^{47}$
Studies have also been conducted to assess a patient's satisfaction with services, such as assessing how users and health professionals perceive satisfaction with the public dental service, ${ }^{48}$ or assessing levels of user satisfaction in different age groups, or the association between user satisfaction and different types of dental services in Brazil. ${ }^{49}$ Other studies ${ }^{50}$ have investigated the factors that influence satisfaction in relation to orthodontic treatment in adults, and have identified five main topics related to patient satisfaction with the treatment process: communication, staff, physical environment, appointments, and impact of dental appliance treatment, highlighting that effective communication was the most dominant topic. Explanations during treatment and the ability of professionals to make patients feel involved in their own care were issues related to this dominant topic. ${ }^{50}$

The above-mentioned studies demonstrated that PREMs are a useful construct for understanding how the patient evaluates the quality of the treatment received. Moreover, the use of PREMs enables a comparison among different treatments, and is also related to a patient's adherence to treatment. Collectively, these features make PREMs important indicators that should be applied in clinical practice.

\section{Conclusion}

PROMs and PREMs have a broad application, and are vital for applying a comprehensive approach in dental clinical trials. Therefore, researchers and clinicians should know how to recognize, choose and apply the most appropriate patient-centered measure.

\section{Acknowledgements}

This study was supported by the Federal University of Minas Gerais (UFMG), Conselho Nacional de Desenvolvimento Científico e Tecnológico - CNPq, and Coordenação de Aperfeiçoamento de Pessoal de Nível Superior - Brasil (CAPES) - Finance Code 001.

\section{References}

1. Institute of Medicine (US). Committee on Quality of Health Care in America. Crossing the quality chasm: a new health system for the 21 st Century. Washington, DC: National Academies Press; 2001. 
Patient-centered assessments: how can they be used in dental clinical trials?

2. Perazzo MF, Gomes MC, Neves ÉT, Martins CC, Paiva SM, Granville-Garcia AF. Oral health-related quality of life and sense of coherence regarding the use of dental services by preschool children. Int J Paediatr Dent. 2017 Sep;27(5):334-43. https://doi.org/10.1111/ipd.12266

3. Sharma NS. Patient centric approach for clinical trials: current trend and new opportunities. Perspect Clin Res. 2015 Jul-Sep;6(3):134-8. https://doi.org/10.4103/2229-3485.159936

4. U.S. Department of Health and Human Services FDA Center for Drug Evaluation and Research. U.S. Department of Health and Human Services FDA Center for Biologics Evaluation and Research, U.S. Department of Health and Human Services FDA Center for Devices and Radiological Health. Guidance for industry: patient-reported outcome measures: use in medical product development to support labeling claims: draft guidance. Health Qual Life Outcomes. 2006 Oct;4(1):79. https://doi.org/10.1186/1477-7525-4-79

5. Santana MJ, Haverman L, Absolom K, Takeuchi E, Feeny D, Grootenhuis M, et al. Training clinicians in how to use patient-reported outcome measures in routine clinical practice. Qual Life Res. 2015 Jul;24(7):1707-18. https://doi.org/10.1007/s11136-014-0903-5

6. Kingsley C, Patel S. Patient-reported outcome measures and patient-reported experience measures. BJA Educ. 2017 Apr;17(4):137-44. https://doi.org/10.1093/bjaed/mkw060

7. Miller D, Steele Gray C, Kuluski K, Cott C. Patient-centered care and patient-reported measures: let's look before we leap. Patient. 2015 Aug;8(4):293-9. https://doi.org/10.1007/s40271-014-0095-7

8. Liu H, Hays RD, Marcus M, Coulter I, Maida C, Ramos-Gomez F, et al. Patient-Reported oral health outcome measurement for children and adolescents. BMC Oral Health. 2016 Sep;16(1):95. https://doi.org/10.1186/s12903-016-0293-x

9. Vries M, Ouwendijk R, Kessels AG, Haan MW, Flobbe K, Hunink MG, et al. Comparison of generic and disease-specific questionnaires for the assessment of quality of life in patients with peripheral arterial disease. J Vasc Surg. 2005 Feb;41(2):261-8. https://doi.org/10.1016/i.jvs.2004.11.022

10. Mehta T, Venkata Subramaniam A, Chetter I, McCollum P. Disease-specific quality of life assessment in intermittent claudication: review [review]. Eur J Vasc Endovasc Surg. 2003 Mar;25(3):202-8. https://doi.org/10.1053/ejvs.2002.1837

11. Tsang S, Royse CF, Terkawi AS. Guidelines for developing, translating, and validating a questionnaire in perioperative and pain medicine. Saudi J Anaesth. 2017 May;11(5 Suppl 1):S80-9. https://doi.org/10.4103/sja.SJA_203_17

12. Tsakos G, Blair YI, Yusuf H, Wright W, Watt RG, Macpherson LM. Developing a new self-reported scale of oral health outcomes for 5-year-old children (SOHO-5). Health Qual Life Outcomes. 2012 Jun;10(1):62. https://doi.org/10.1186/1477-7525-10-62

13. Benítez I, Padilla JL, Ongena Y. Analysis of quality of proxy questions in health surveys by behavior coding. West J Nurs Res. 2012 Nov;34(7):917-32. https://doi.org/10.1177/0193945910388049

14. Teale EA, Young JB. A Patient Reported Experience Measure (PREM) for use by older people in community services. Age Ageing. 2015 Jul;44(4):667-72. https://doi.org/10.1093/ageing/afv014

15. Sischo L, Broder HL. Oral health-related quality of life: what, why, how, and future implications. J Dent Res. 2011 Nov;90(11):1264-70. https://doi.org/10.1177/0022034511399918

16. Baker SR. Testing a conceptual model of oral health: a structural equation modeling approach. J Dent Res. 2007 Aug;86(8):708-12. https://doi.org/10.1177/154405910708600804

17. Locker D, Jokovic A, Tompson B. Health-related quality of life of children aged 11 to 14 years with orofacial conditions. Cleft Palate Craniofac J. 2005 May;42(3):260-6. https://doi.org/10.1597/03-077.1

18. Mittal H, John MT, Sekulić S, Theis-Mahon N, Rener-Sitar K. Patient-reported outcome measures for adult dental patients: a systematic review. J Evid Based Dent Pract. 2019 Mar;19(1):53-70. https://doi.org/10.1016/i.jebdp.2018.10.005

19. Chen MS, Hunter P. Oral health and quality of life in New Zealand: a social perspective. Soc Sci Med. 1996 Oct;43(8):1213-22. https://doi.org/10.1016/0277-9536(95)00407-6

20. Meireles SS, Goettems ML, Dantas RV, Bona ÁD, Santos IS, Demarco FF. Changes in oral health related quality of life after dental bleaching in a double-blind randomized clinical trial. J Dent. 2014 Feb;42(2):114-21. https://doi.org/10.1016/i.jdent.2013.11.022

21. Čelebić A, Peršić S, Kovačić I, Buković D, Lešić N, Rener-Sitar K. Comparison of three prosthodontic treatment modalities for patients with periodontally compromised anterior mandibular teeth: a 2-year follow-up study. Acta Stomatol Croat. 2019 Mar;53(1):4-16. https://doi.org/10.15644/asc53/1/1

22. Li L, Wang $H$, Han X. Oral health-related quality of life in pediatric patients under general anesthesia: a prospective study. Medicine (Baltimore). 2017 Jan;96(2):e5596. https://doi.org/10.1097/MD.0000000000005596

23. Geramy A, Mazaheri Nazarifar A, Saffar Shahroudi A, Sheikhzadeh S. Oral health-related quality of life following orthognathic surgery for class III correction its relationship with cephalometric changes. Int J Oral Maxillofac Surg. 2019 Nov;48(11):1434-9. https://doi.org/10.1016/i.ijom.2019.03.899

24. Lima TC, Vieira-Barbosa NM, Azevedo CGS, Matos FR, Oliveira DWD, de Oliveira ES, et al. Oral health-related quality of life before and after treatment of dentin hypersensitivity with cyanoacrylate and laser. J Periodontol. 2017 Feb;88(2):166-72. https://doi.org/10.1902/jop.2016.160216 
25. Zanin RF, Ommizolo G, Weber A, Heitz C, de Lima EM. Oral health-related quality of life in women with temporomandibular joint disk anterior displacement before and after disk repositioning and anchoring surgery assessed with the Oral Health Impact Profile (OHIP-14). Oral Surg Oral Med Oral Pathol Oral Radiol. 2019 Aug;128(2):112-6. https://doi.org/10.1016/j.0000.2019.05.005

26. International Association for the Study of Pain. Classification of chronic pain. Seattle: IASP PRESS; 1994.

27. Fitzgerald M. The development of nociceptive circuits. Nat Rev Neurosci. 2005 Jul;6(7):507-20. https://doi.org/10.1038/nrn1701

28. Fearon I, McGrath PJ, Achat H. 'Booboos': the study of everyday pain among young children. Pain. 1996 Nov;68(1):55-62. https://doi.org/10.1016/S0304-3959(96)03200-9

29. Versloot J, Veerkamp JS, Hoogstraten J. Dental discomfort questionnaire: assessment of dental discomfort and/or pain in very young children. Community Dent Oral Epidemiol. 2006 Feb;34(1):47-52. https://doi.org/10.1111/j.1600-0528.2006.00253.x

30. Boeira GF, Correa MB, Peres KG, Peres MA, Santos IS, Matijasevich A, et al. Caries is the main cause for dental pain in childhood: findings from a birth cohort. Caries Res. 2012;46(5):488-95. https://doi.org/10.1159/000339491

31. Freire MC, Jordão LM, Peres MA, Abreu MH. Six-year trends in dental pain and maternal education inequalities among Brazilian adolescents. Community Dent Oral Epidemiol. 2019 Dec;47(6):454-60. https://doi.org/10.1111/cdoe.12483

32. Wijk AJ, Hoogstraten J. Experience with dental pain and fear of dental pain. J Dent Res. 2005 Oct;84(10):947-50. https://doi.org/10.1177/154405910508401014

33. Svensson L, Hakeberg M, Wide U. Dental pain and oral health-related quality of life in individuals with severe dental anxiety. Acta Odontol Scand. 2018 Aug;76(6):401-6. https://doi.org/10.1080/00016357.2018.1473892

34. Peretz B, Sarnat H. Relations between dental and somatic pain in children. Int J Paediatr Dent. 2010 May;20(3):201-6. https://doi.org/10.1111/j.1365-263X.2010.01041.x

35. Gandhi M, Thomson C, Lord D, Enoch S. Management of pain in children with burns. Int J Pediatr. 2010;2010:1-9. https://doi.org/10.1155/2010/825657

36. Hayes M, Patterson D. Experimental development of the graphic rating method. Psychol Bull. 1921;18:98-9.

37. Morone NE, Weiner DK. Pain as the fifth vital sign: exposing the vital need for pain education. Clin Ther. 2013 Nov;35(11):1728-32. https://doi.org/10.1016/i.clinthera.2013.10.001

38. Melzack R. The short-form McGill Pain Questionnaire. Pain. 1987 Aug;30(2):191-7. https://doi.org/10.1016/0304-3959(87)91074-8

39. Pau A, Croucher R, Marcenes W, Leung T. Development and validation of a dental pain-screening questionnaire. Pain. 2005 Dec;119(13):75-81. https://doi.org/10.1016/i.pain.2005.09.016

40. Tung AW, Kiyak HA. Psychological influences on the timing of orthodontic treatment. Am J Orthod Dentofacial Orthop. 1998 Jan;113(1):29-39. https://doi.org/10.1016/S0889-5406(98)70274-4

41. Lajnert V, Kovacevic Pavicic D, Pavlic A, Pokrajac-Bulian A, Spali S. Smile Aesthetics Satisfaction Scale: development and validation of a new brief five-item measure of satisfaction with smile aesthetics in adults and the elderly. Int Dent J. 2018 Jun;68(3):162-70. https://doi.org/10.1111/idj.12362

42. Birkeland K, Katle A, Løvgreen S, Bøe OE, Wisth PJ. Factors influencing the decision about orthodontic treatment. A longitudinal study among 11- and 15-year-olds and their parents. J Orofac Orthop. 1999;60(5):292-307. https://doi.org/10.1007/BF01301243

43. Kaieda AK, Bulgareli JV, Cunha IP, Vedovello SA, Guerra LM, Ambrosano GM, et al. Malocclusion and dental appearance in underprivileged Brazilian adolescents. Braz Oral Res. 2019 Mar;33:e014. https://doi.org/10.1590/1807-3107bor-2019.vol33.0014

44. Carlsson V, Hakeberg M, Blomkvist K, Wide Boman U. Orofacial esthetics and dental anxiety: associations with oral and psychological health. Acta Odontol Scand. 2014 Nov;72(8):707-13. https://doi.org/10.3109/00016357.2014.898786

45. Isiekwe Gl, Aikins EA. Self-perception of dental appearance and aesthetics in a student population. Int Orthod. 2019 Sep;17(3):506-12. https://doi.org/10.1016/i.ortho.2019.06.010

46. Cunha MC, Santos JF, Santos MB, Marchini L. Patients' expectation before and satisfaction after full-arch fixed implant-prosthesis rehabilitation. J Oral Implantol. 2015 Jun;41(3):235-9. https://doi.org/10.1563/AAID-JOI-D-12-00134

47. Pachêco-Pereira C, Pereira JR, Dick BD, Perez A, Flores-Mir C. Factors associated with patient and parent satisfaction after orthodontic treatment: a systematic review. Am J Orthod Dentofacial Orthop. 2015 Oct;148(4):652-9. https://doi.org/10.1016/i.ajodo.2015.04.039

48. Bordin D, Fadel CB, Moimaz SA, Garbin CA, Saliba NA. Comparative study of satisfaction of users and health professionals with the public dental service. Cien Saude Colet. 2017 Jan;22(1):151-60. https://doi.org/10.1590/1413-81232017221.13522015

49. Macarevich A, Pilotto LM, Hilgert JB, Celeste RK. User satisfaction with public and private dental services for different age groups in Brazil. Cad Saude Publica. 2018 Feb;34(2):e00110716. https://doi.org/10.1590/0102-311×00110716

50. Wong L, Ryan FS, Christensen LR, Cunningham SJ. Factors influencing satisfaction with the process of orthodontic treatment in adult patients. Am J Orthod Dentofacial Orthop. 2018 Mar;153(3):362-70. https://doi.org/10.1016/i.ajodo.2017.07.017 